\title{
Evidence of Long-Term Trend of Visibility in the Sahel and Coevolution with Meteorological Conditions and Vegetation Cover during the Recent Period
}

\author{
Siélé Silué1*, Touré E. N’Datchoh², Arona Diedhiou²,3, Emmanuel Quansah4, Madina Doumbia² \\ ${ }^{1}$ Université Peleforo Gon Coulibaly, Korhogo, Côte d'Ivoire \\ ${ }^{2}$ LAPA-MF, Université Félix Houphouët-Boigny, Abidjan, Côte d'Ivoire \\ ${ }^{3}$ IGE, CNRS Grenoble INP, IRD, Université Grenoble Alpes, Grenoble, France \\ ${ }^{4}$ Kwame Nkrumah University of Science and Technology, Kumasi, Ghana \\ Email: *sielesil@yahoo.fr, *sielesilue@upgc.edu.ci,ndatchoh.toure@univ-fhb.edu.ci,doumbiamadina@yahoo.fr, \\ arona.diedhiou@ird.fr, equansah.cos@knust.edu.gh
}

How to cite this paper: Silué, S., N’Datchoh, T.E., Diedhiou, A., Quansah, E. and Doumbia, M. (2019) Evidence of Long-Term Trend of Visibility in the Sahel and Coevolution with Meteorological Conditions and Vegetation Cover during the Recent Period. Atmospheric and Climate Sciences, 9, 346-368. https://doi.org/10.4236/acs.2019.93025

Received: February 14, 2019

Accepted: July 8, 2019

Published: July 11, 2019

Copyright () 2019 by author(s) and Scientific Research Publishing Inc. This work is licensed under the Creative Commons Attribution International License (CC BY 4.0).

http://creativecommons.org/licenses/by/4.0/

(c) (i) Open Access

\begin{abstract}
In this study, the long term trend of the observed visibility data used directly (without conversion into dust concentrations) over Sahel was investigated between 1957 and 2013. Then, to review the influence of atmospheric factors and land surface conditions on this trend, the coevolution between the visibility and the dust surface mass concentration from MERRA-2 (Modern-Era Retrospective analysis for Research and Applications) reanalysis, the in-situ surface meteorological data (rainfall, relative humidity, wind speed, and air temperature), as well as the Normalized Difference Vegetation Index (NDVI) were analyzed from 2000 to 2013 . We showed that the horizontal visibility has significantly decreased since the 1970s. The coevolution between the visibility and the dust surface mass concentration revealed that visibility decreased significantly with increments in dust concentrations. Visibility increases with rainfall and relative humidity. It is greater in areas of high vegetation cover than in deforested areas. Visibility is weakly correlated with wind speed and air temperature but generally, wind leads to a decrease in visibility, while warm air temperature is associated with a clearer sky and hence, high visibility. The worst visibility in the dry season results from high dust concentrations due to warm and dry wind conditions and less vegetation cover. Rainfall, relative humidity and vegetation cover are the dominant factors contributing to the decrease of dust loading in the Sahel.
\end{abstract}




\section{Keywords}

Visibility, Dust, Climate, Vegetation, Sahel

\section{Introduction}

The increase of Aeolian processes observed in most arid and semi-arid areas of the world over the last decades has been observed to be responsible for the environmental stresses and global climate change [1] [2] [3]. Mineral dust has a strong impact on the climate system through direct and indirect means [4] [5]. African dust emission and transport affect the climate and it is also in return influenced by the climate. Previous works have shown that there is an increase in dust emission and transport over the Atlantic during periods of the Sahelian drought, due to a decrease in soil moisture and an increase in surface wind speeds or a combination of the two over the Sahara [2] [6] [7] [8].

The vast majority of North African dust emissions occur within largely uninhabited regions and thus, there is a paucity of both meteorological and surface observations in these locations, particularly homogeneous measurements of each that span time scales of years to decades [9]. In this regard, numerical models play a crucial role in understanding the processes. However, there are relatively few observational data sets available for the validation of the simulated dust concentrations. Therefore, models are often validated using surface visibility observations from a limited number of sampling stations and retrievals of aerosol optical depth from satellites and ground-based instrumentations, none of them is based on direct measurements of dust concentrations [10]. Although the use of visibility as a viable atmospheric variable has been discussed by many researchers due to the numerous biases related to observational procedures [11], visibility statistics have been increasingly used as a surrogate for aerosol loads [12], especially since visibility records span a long period of time. In recent years, several studies have used visibility observational data to investigate the spatial and temporal variation of the optical properties of the atmosphere, mainly with respect to pollutants emissions and aerosol loads [13] [14].

There is an increasing interest in quantifying the mineral dust concentration over North Africa, the most important dust source of the world [15] [16] [17]. However, air quality monitoring stations in rural sites or near dust sources over Northern Africa are scarce. To overcome this strong observational limitation, horizontal visibility obtained from meteorological reports, Surface Synoptic Observations (SYNOP) has been used to infer surface dust concentrations [18] [19]. Horizontal visibility is an indicator of the attenuation of solar radiation intensity by suspended particles [20]. It is strongly influenced by dust particle size distribution and also has a clear dependence on the ambient humidity [21]. Many studies have shown that horizontal visibility is a good indicator of dust storms [19] [20]. Windborne dust, due to their frequency, density and geographical ex- 
tent are one of the important characteristics of the West African climate [18] [19]. The Sahara and Sahel regions are often subjected to dust, which reduces horizontal visibility to $5 \mathrm{~km}$, and sometimes to less than $1 \mathrm{~km} \mathrm{[18]} \mathrm{[20].} \mathrm{Previous}$ studies on the visibility reduction associated with dust-related weather have provided fundamental information on the spatial and temporal characteristics of dust activities [20] [22] [23] [24].

Estimates of dust concentrations can be derived from visibility measurements [18] [19] [23] [25] [26]. In addition, Tsai et al. [27] indicated that the long-term trend in visibility can be used to assess past, current and future air pollution control measures. Until now, the application of visibility data for dust studies has been constrained by the scarcity of direct measurements of coincident dust concentration and visibility measurements.

The mineral dust loading in the atmosphere varies greatly from year to year [6]. Previous works investigating such interannual variability focused on the quantity of mineral dust crossing the Atlantic Ocean and reaching the Americas [8]. These large interannual changes and the downward trend highlight the importance of climate feedbacks on natural aerosol abundance [2]. The Sahara contains some of the most productive dust sources [28] but the interannual and seasonal variability of the Sahel sources are mostly sensitive to rainfall, vegetation, and wind field changes [6] [29] [30]. Vegetation and rainfall have increased across the Sahel since the mid-1980s [31]. At the same time, surface observations of visibility across northern Africa [19] and satellite estimates over the downstream tropical Atlantic [32] and Sahel [33] indicate a downward trend in dustiness since mid-1980s. There are concurrent observations of weaker winds over the Sahel [19], but the mechanisms linking these trends have not been established.

This study aims not only to investigate the temporal variations of visibility in Sahelian zone, but also to analyze the relationship between visibility, meteorological factors and vegetation cover. The paper is structured as follow: data and method used are described in Section 2, results are presented in Section 3, and in Section 4 the main conclusions are summarized.

\section{Material and Method}

Visibility data are available at three hourly intervals over much of the last century at many meteorological stations located in Africa and throughout the world [19]. We use the seven Sahelian stations of Nouakchott (World Meteorological Organization station number 61442), Nouadhibou (61415), Dakar (61641), Tambacounda (61687), Bamako (61291), Niamey (61052), and N'djamena (64700) (see Figure 1 for locations), which are part of the standard Surface Synoptic Observations (SYNOP) surface observation network. All seven (7) stations are located in the semi-arid Sahel zone of West Africa in an area extending from $10^{\circ} \mathrm{N}$ to $22^{\circ} \mathrm{N}$ and from $20^{\circ} \mathrm{W}$ to $20^{\circ} \mathrm{E}$.

In addition, daily data are available only for the following four (4) periods: 1957-1961, 1970-1974, 1983-1987 and 1997-2013. Reasons of the lack of data 


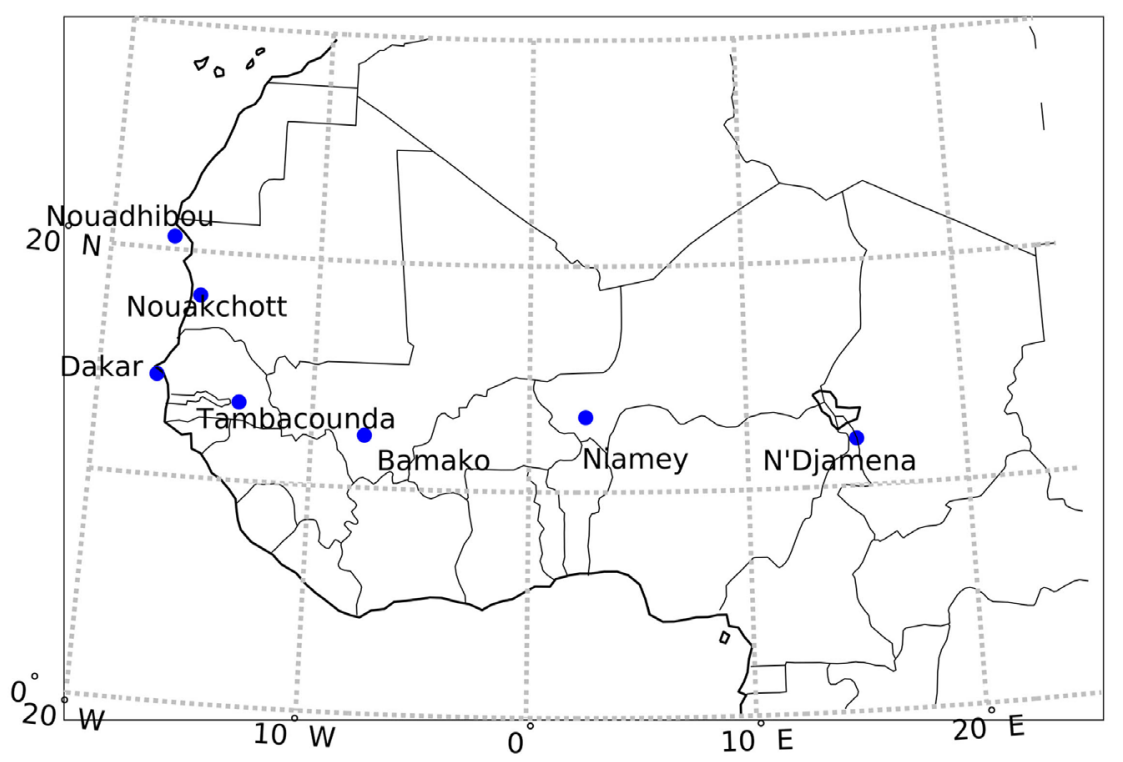

Figure 1. Map showing the locations of the seven Sahelian stations used in this study.

between these periods are unknown. Mbourou et al. [20] used the same data with the same gaps since 1987. For this study, the time series on the same stations has been completed from 1997 to 2013. These stations correspond to airports or airfields, at which low visibility observations are performed. The visibility data set consists of meteorological records reported at 3 hourly intervals $(0000,0300,0600,0900,1200,1500,1800$ and 2100 UTC) in SYNOP every day from 1957 to 2013, in accordance with standards of Agence pour la Securité de la Navigation Aérienne en Afrique et Madagascar(ASECNA) procedures. Other meteorological data such as temperature, relative humidity (RH), precipitation and wind speed (WS) were also recorded at these times.

Meteorological observers define a dust event when visibility is reduced below a specified level due to the presence of dust in the near-surface layers of the atmosphere. The frequency of dust event measurement will thus be determined by the proximity of the recording station to a source and to the strength of that source. The dust event records are classified according to visibility into the following categories: 1) dust in suspension: widespread dust in suspension, not raised at or near the station at the time of observation; visibility is usually not greater than $10 \mathrm{~km}, 2$ ) blowing dust: raised dust or sand at the time of observation, reducing visibility to 1 to $10 \mathrm{~km}, 3$ ) dust storm: strong winds lift large quantities of dust particles, reducing visibility to between 200 and $1000 \mathrm{~m}$, and 4) severe dust storm: very strong winds lift large quantities of dust particles, reducing visibility to less than $200 \mathrm{~m}$. The annual values of visibility and meteorological variables were obtained from monthly averages derived from daily data of the seven stations. Meteorological data from 2000 to 2013 were obtained from Weather Underground portal (https://www.wunderground.com), which is a weather service providing free online weather information in real time for most major cities across the world. International current conditions are collected di- 
rectly from more than 29,000 weather stations located in countries around the globe including about 6000 automated weather stations operating at airports. Typically these stations are owned by government agencies and international airports and data is updated at 1,3, or 6 hour intervals, depending upon the station. When a visitor requests current conditions from wunderground.com, the geographically closest station is displayed. There is also a "Station Select" button, which shows a list of the closest stations.

Changes in vegetation from 2000 to 2013 are derived from monthly variation of MODIS Normalized Difference Vegetation Index (NDVI) at $0.05^{\circ} \times 0.05^{\circ}$ resolution obtained from https://modis.gsfc.nasa.gov/data/dataprod/mod13.php.

Contrarily to previous works which converted visibilities into dust concentration [18] [19] [23], the visibility in this study is used as it is (without conversion into dust concentrations) to investigate the long term trends of atmospheric visibility between 1957 and 2013 in the Sahel, and their relationships with meteorological factors such as rainfall, wind speed (WS), relative humidity (RH), air temperature (T), MERRA-2 Dust Surface Mass Concentration and vegetation cover for the period 2000-2013.

The evaluation of the meteorological conditions was limited to the period 2000 to 2013, because most of the stations had complete records within this period. The relation between meteorological conditions and visibility (thus, dust emissions) has been investigated in comparing their annual coevolution from 2000 to 2013 in dry season (DS, from October to May) and in rainy season (RS, from June to September). The data for this study were analysed using tables, graphs and correlations.

\section{Results and Discussion}

\subsection{Inter-Decadal Variation of the Annual Mean Visibility in the Sahel}

Trends in annual visibility in the Sahel from 1957 to 2013 are showed in Figure 2. A general decreasing trend in visibility is noted from 1970s to 1980s and a relative stability is observed after 1997. Visibility levels are remarkably higher in the first sub-period (1957 to 1961) reaching an average of $26 \mathrm{~km}$. This sub-period 1 is followed by a gradual deterioration from 1970 onwards. The visibility shows a worsening trend in the second sub-period (1970 to 1974) and in the third sub-period (1983 to 1987). In the second sub-period from 1970 to 1974, the annual average visibility is less than $16 \mathrm{~km}$ while in the third sub-period, the annual average visibility is less than $12 \mathrm{~km}$. Visibility degradation during sub-periods 2 and 3 had been associated with extended drought period in the whole Northern African region [19] [20] [22]. Previous studies from satellites and surface measurements revealed a significantly downward trend in Dust Aerosol Optical Depth (DAOD) in the region since the 1980s, persisting through both summer and winter seasons [2] [16]. While a significant shift in the visibility is noted between the two decades 1970s and 1980s, the visibility in the last two 


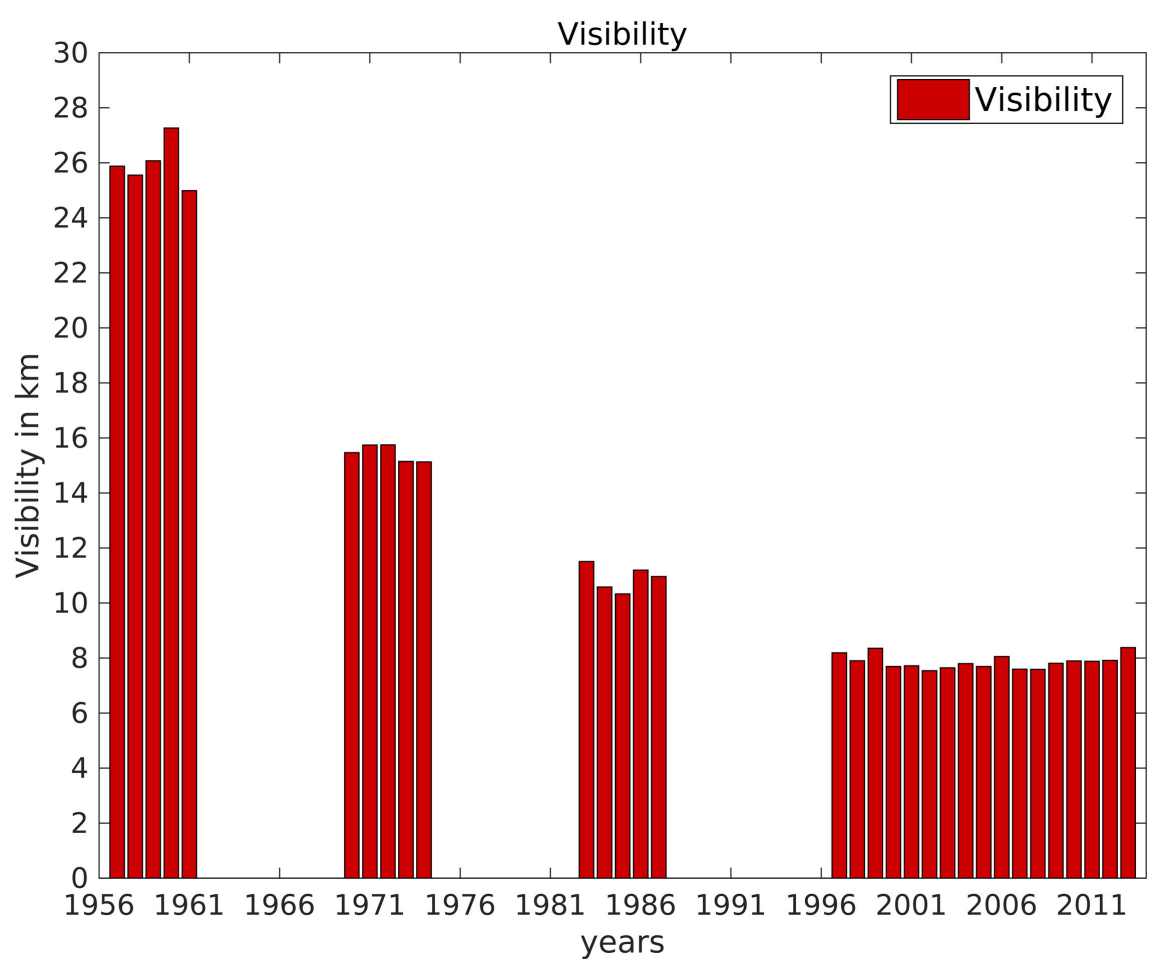

Figure 2. Inter-decadal variability of the annual averaged visibility from 1957 to 2013 in the Sahel.

decades (from 1997 to 2013) is the weakest visibility and has no clear trend. A number of earlier studies conducted in other countries have also reported the presence of decreasing trends in annual visibility in urban areas [13] [27] [34] [35]. This situation was mostly due to meteorological conditions and air pollution.

Since the 1980s, a dramatic downward trends in North African dustiness and transport to the tropical Atlantic Ocean have been observed by different data sets and methods [6] [7] [36]. The precise causes of these trends have previously been difficult to understand, partly due to the sparse observational records [7]. Several studies focused on explaining this change by linking the observed dust load with climate indexes such as large scale sea surface temperature [6] [36].

\subsection{Relationship between Visibility, Meteorological Factors and Vegetation Cover}

In studies of atmospheric turbidity the visibility, on one hand, aerosol optical thickness and shortwave surface irradiance are linked parameters [25]. On the other hand, the production of dust and its entrainment into the atmosphere combines meteorology and surface properties. During its residence time into the atmosphere, dust interacts with solar radiation and thus induces into changes such as in surface temperature, wind, clouds, and precipitation rates [37] [38]. In this study, we investigated changes in dry season (DS) and rainy season (RS) of various meteorological controlling factors and vegetation to understand the trend 
of dust concentrations using visibility (hereafter VISI) observed during the period 2000-2013. The meteorological variables are: wind speed (WS), rainfall, relative humidity $(\mathrm{RH})$, temperature (T) and vegetation cover (NDVI).

Table 1 shows the correlation matrix of monthly visibility, MERRA dust concentration (DC), meteorological factors and vegetation cover (NDVI) from 2000 to 2013 in the Sahel. Atmospheric visibility is significantly related to the six (6) parameters (dust concentration, wind speed, rainfall, relative humidity, temperature, and NDVI) with absolute values of correlation coefficients ranging from 0.49 to 0.91 . At monthly time scale, there are negative correlations between visibility and dust concentration and wind speed, an indication that visibility decreases under months with high dust concentration or high wind speed conditions. In contrast, visibility is positively correlated in months with more rainfall, relative humidity, temperature and NDVI. The results also showed that dust concentration has high positive correlation coefficients with wind speed and negative correlations coefficients with rainfall, relative humidity, temperature and NDVI.

\subsection{Interannual Coevolution of Visibility and Dust Surface Mass Concentration}

Previous works examining correlation between visibility and aerosol characteristic have made clear the heterogeneous concentration of aerosols in the atmosphere, the changes atmospheric optical conditions and thus, visibility [26]. Figure 3 displays the coevolution between the horizontal visibility and the dust surface mass concentration values in the Sahel region from 2000 to 2013 during the dry (a) and the rainy (b) seasons. The inter-annual evolution of visibility and dust concentrations shows that an increase in dust concentration is associated with a considerable reduction in horizontal visibility. A high concentration of airborne particulate matter was therefore, closely related to the impairment of visibility accordingly to the high value of correlation coefficient in Table 1 $(-0.91)$. Better visibilities are found during the rainy season with the highest values of $8.94 \mathrm{~km} \mathrm{(2011)} \mathrm{and} 8.95 \mathrm{~km}$ (2012). The highest dust surface mass

Table 1. Correlation matrix of monthly visibility, dust concentration, meteorological factors and vegetation (NDVI) obtained from the Sahel between 2000 and 2013.

\begin{tabular}{cccccccc}
\hline & Visi. & Dust Con. & Wind Speed & Rainfall & R Humidity & Temp. NDVI \\
\hline Visibility & 1 & - & - & - & - & - & - \\
Dust Concentration & -0.91 & 1 & - & - & - & - & - \\
Wind Speed & -0.49 & 0.57 & 1 & - & - & - & - \\
Rainfall & 0.76 & -0.71 & -0.41 & - & - & - & - \\
Relative Humidity & 0.87 & -0.81 & -0.44 & 0.87 & 1 & - & - \\
Temperature & 0.58 & -0.48 & -0.14 & 0.26 & 0.47 & 1 & - \\
NDVI & 0.76 & -0.77 & -0.79 & 0.78 & 0.82 & 0.23 & 1 \\
\hline
\end{tabular}




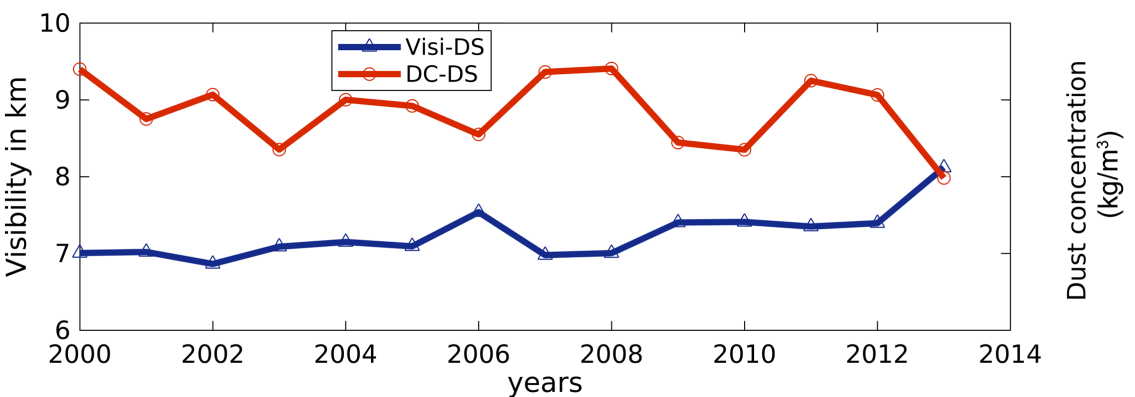

(a)

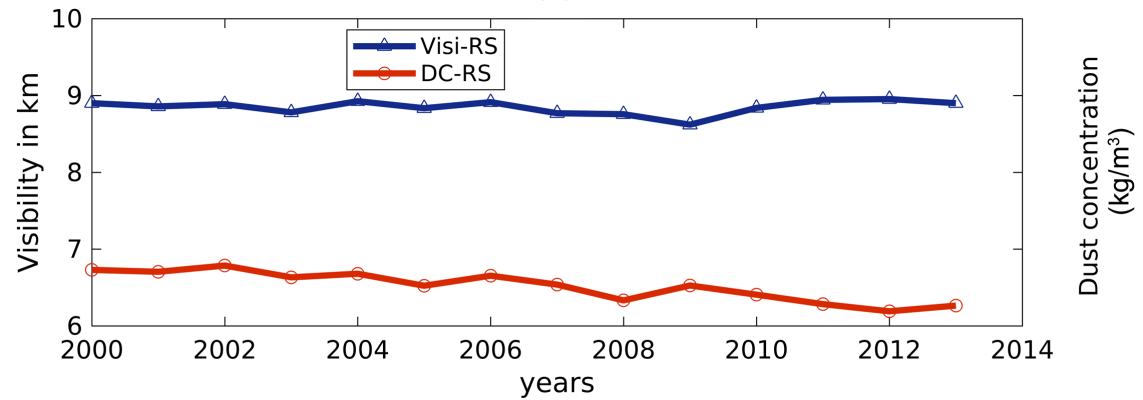

(b)

Figure 3. Evolution of visibility and dust concentration in the Sahel from 2000 to 2013 for (a) the dry season and (b) the rainy season.

concentrations are found in the dry season with values of $4.12 \times 10^{-7} \mathrm{~kg} \cdot \mathrm{m}^{-3}$ and $4.13 \times 10^{-7} \mathrm{~kg} \cdot \mathrm{m}^{-3}$ in 2000 and 2008 respectively. The dry season's averaged visibility range between $6.86 \mathrm{~km}(2002)$ and $8.12 \mathrm{~km} \mathrm{(2013)}$ and the rainy season dust concentrations vary between $2.12 \times 10^{-7} \mathrm{~kg} \cdot \mathrm{m}^{-3}(2012)$ and $2.49 \times 10^{-7}$ $\mathrm{kg} \cdot \mathrm{m}^{-3}$ (2002) respectively.

The dust concentration in dry season has a larger interannual variance than in wet season. High dust surface mass concentration corresponds to low visibility and vice versa. However, years with the highest dust concentration are not the same than weakest years of visibility and vice versa. This difference between these extreme years confirms that there are several atmospheric and climatic factors, as well as land surface conditions that influence the visibility. Hence, visibility is affected by ambient air pollutant concentrations and meteorological conditions. For instance, the reduction in visibility is directly proportional to the loading of airborne particulate matter (PM) [18]. Moreover, the Sahel belt is known to be a region where atmospheric levels of suspended mineral dust are among the highest observed on Earth [15] [16]. Since visibility is influenced by the prevailing meteorological conditions [11] [39], it is expected that it will also exhibit a seasonal variability. During the dry season, the Sahara dust laden into atmosphere by the Harmattan wind attenuates visible solar radiation much stronger than the hydrometeors in the raining season [24]. The dry weather also enhances dust emission and transport from the main sources, as well as at the regional scale. Furthermore, the period is characterized by increase of anthropogenic emissions due to biomass burning and grazing after harvest [40] [41]. As there is quite no moisture to either reduce visibility or cause hydroscopic 
growth or clouds which could also reduce visibility [19], the high correlation coefficient between visibility and dust concentration confirms that airborne particle outbreaks are the major factor controlling the visibility in the Sahel region during the dry season.

It has been demonstrated by previous studies that atmospheric visibility is greatly influenced by particulate matter (PM) in many parts of the world [42] [43]. In Northern Africa, D'Almeida [42] established a widely known and used empirical relationship between horizontal visibility and aerosol mass concentration. Mohamed et al. [43] used horizontal visibility data varying from $100 \mathrm{~m}$ to $20 \mathrm{~km}$ in the synoptic station located at Niamey Airport (Niger), over a period of 17 months (from February 1986 to June 1987), and associated Total Suspended Particles from mineral dust mass concentration measurements in order to establish a relationship between the two parameters. Also, Ozer et al. [18] estimated the impact of mineral dust resulting from aeolian processes on air quality degradation throughout the year 2000 at Nouakchott Airport (Mauritania), using the relations established by [42] and [43]. Camino et al. [44] obtained a new empirical equation relating horizontal visibility and PM10 concentration using observations performed at the Izana Atmospheric Observatory (IZO, $28.30^{\circ} \mathrm{N}$, $16.49^{\circ} \mathrm{W}, 2367 \mathrm{~m}$ a.s.l, Tenerife, Spain) under Saharan dust outbreaks from 2003 to 2010. Lin et al. [34] showed that visibility impairment was generally accompanied by airborne particulate matter (PM), especially fine particles with aerodynamic diameters of $2.5 \mu \mathrm{m}$ and less (PM2.5), due to their light-scattering and absorption capabilities. Other studies [21] [24] [41] [45] [46] [47] have found that a high concentration of fine particulate matter was closely related to the impairment of visibility. Founda et al. [13] showed that visibility in Athens was highly determined by aerosol loads of regional origin. Satellite derived aerosol optical depth (AOD) retrievals over Athens since 2000, and surface measurements of PM10 confirmed the relation of visibility with aerosol loads.

\subsection{Interannual Coevolution of Visibility and Wind Speed}

Aeolian dust, resulting from wind erosion, is controlled by two major factors: Aeolian erosivity (wind speed) and Aeolian erodibility (land surface conditions) [48]. Under a certain wind threshold, called the wind erosion threshold [49] or the threshold friction velocity [35], the particles cannot be entrained. This threshold depends on the surface properties, including surface roughness, particles size and composition, humidity. This threshold is usually reported to be 5 to 6 $\mathrm{m} \cdot \mathrm{s}^{-1}$, while the most intense emissions occur when the surface wind exceeds 8 to $10 \mathrm{~m} \cdot \mathrm{s}^{-1}$ [49], where mineral particles uplifted from bare soils by winds, may stay in suspension for few days to weeks allowing their transport along thousands of kilometres [17].

Wind erosion over North Africa is responsible for $25 \%$ to $50 \%$ of the global emissions of mineral dust [50]. The Sahel is prone to intense soil erosion, and the dust emission flux is very sensitive to the surface wind speed. Consequently, atmospheric concentrations of particulate matter less than $10 \mu \mathrm{m}$ (PM10) fre- 
quently reach very high values, up to several thousands of $g \cdot \mathrm{m}^{3}$ [18].

Figure 4 displays mean annual visibility and wind speed (WS) during dry (a) and rainy (b) seasons in the Sahel region from 2000 to 2013. This figure shows that there is a good yearly relationship between horizontal visibility (variations and peaks) and wind speed with a decrease in the wind speed and an increase in visibility between 2000 and 2013. An increase in wind speed leads to a reduction in visibility (correlation coefficient of -0.49 in Table 1 ) and an increase of dust surface mass concentration (correlation coefficient of 0.57 ).

The highest wind speeds are found during the dry season with maximum value of $4.44 \mathrm{~m} \cdot \mathrm{s}^{-1}$ in 2000 (Figure 4(a)). The impact of wind speed on visibility is stronger during the dry season. The highest surface wind speed in the dry season could partly explain the worst visibility observed during the dry season. Wind is a crucial factor controlling not only dust emission but also dust transportation [18] [50]. Lin et al. [34] and Zhao et al. [51] showed that calm winds prohibit the transport of pollutants and favour the accumulation of PM, leading to higher PM10 concentrations and worse visibility. Cowie et al. [7] suggested that the recently observed dramatic decadal trends in dustiness over North Africa and the tropical North Atlantic were related to a reduction in dust emission over the Sahel, associated with reduced wind peaks rather than changes in emission threshold. However, high wind speed in urban areas could increase atmospheric visibility, because the wind derived atmospheric mixing results in lower particle concentrations [52]. High wind speed also improves visibility by enhancing the dispersive capability of the atmosphere via thermal and mechanical turbulence

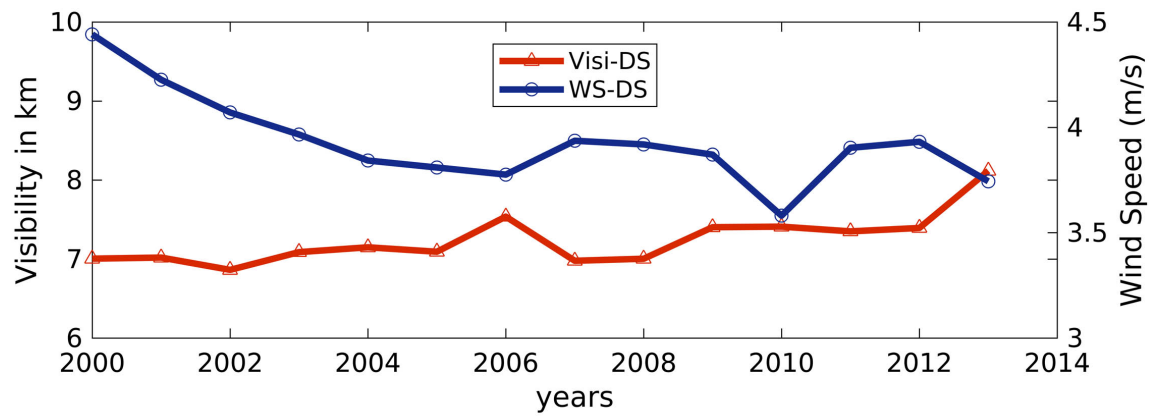

(a)

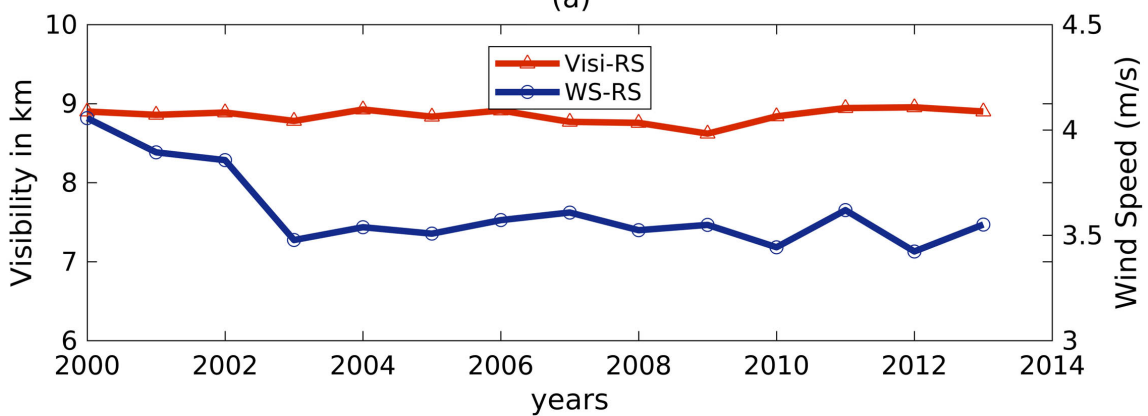

(b)

Figure 4. Evolution of visibility and wind speed in the Sahel from 2000 to 2013 for (a) the dry season and (b) the rainy season. 
and the reduction of aerosol concentration levels [34]. Founda et al. [13] showed that apart from wind speed, visibility was also found to be sensitive to wind direction.

\subsection{Interannual Coevolution of Visibility and Rainfall}

Rainfall is a dust limiting factor by reducing atmospheric dust concentrations through the process of wet deposition. Rainfall and its subsequent impact on soil conditions and surface composition can enhance or suppress dust emission on diurnal to inter-annual timescales through different mechanisms [29]. On one hand, precipitation is associated with scavenging of atmospheric particles, possibly resulting to improvement of visibility. Rainy days on the other hand are associated with increased relative humidity, resulting in reduction of visibility. Figure 5 displays visibility and rainfall changes from 2000 to 2013. Generally, visibility increases with rainfall and vice versa, in agreement with positive correlation (0.76) showed in Table 1 and with negative correlation $(-0.71)$ between rainfall and dust concentration, suggesting that rainfall lowers the dust concentration through precipitation scavenging, and thereby increases the atmospheric visibility. A stronger precipitation leads to more washouts of dust and thus to higher atmospheric visibility.

Goudie and Middleton [53] suggested that phase of increased dustiness in Northern Africa are associated with period of reduced rainfall conditions especially in the Sahel. In addition, high wind speeds during dry season (Figure 4) or drought periods may favour local emission of dust aerosols and greatly increase

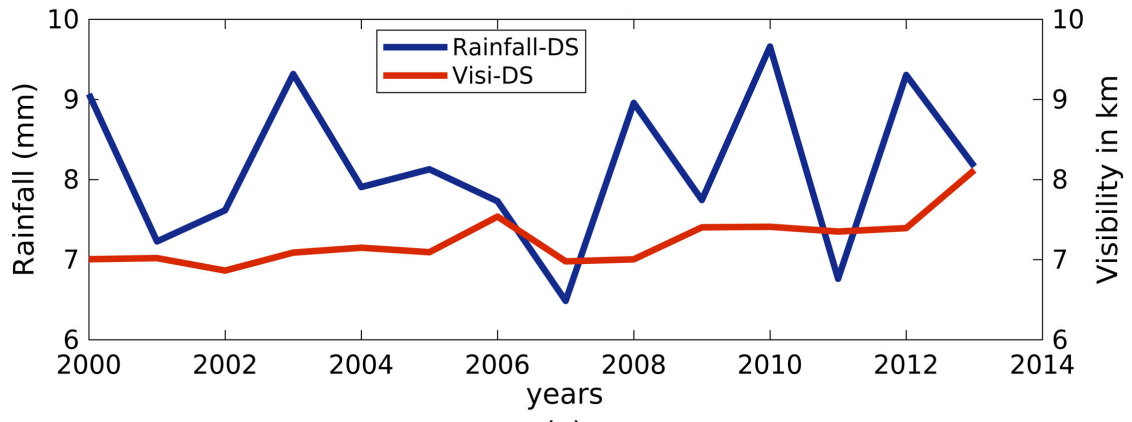

(a)

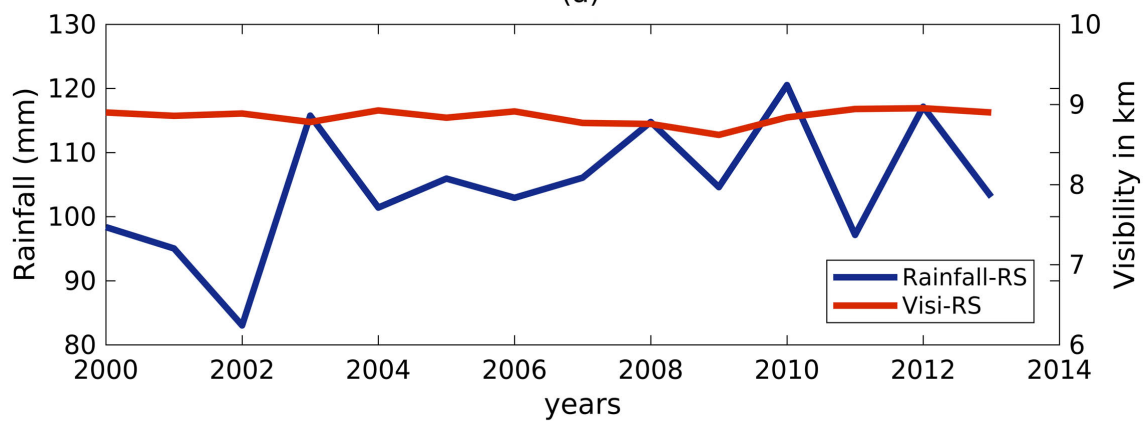

(b)

Figure 5. Evolution of visibility and rainfall in the Sahel from 2000 to 2013 for (a) the dry season and (b) the rainy season. 
dust load therefore affecting the atmospheric visibility. Low rainfall would also prolong the lifespan of dust aerosols in the atmosphere, contributing to enhance weakness of the visibility. Engelstaedter et al. [50] showed that the annual dust cycle may be partly explained by seasonal changes in the positions of the Intertropical Convergence Zone (ITCZ) and associated rainfall distributions. Also, Rosenfeld et al. [1], suggested that rainfall amounts reduction lead to drier soil conditions and less vegetation. Increasing exposure of soil to wind shear and soil moisture reduction, in turn, enhance dust mobilization which further increases dust concentration in the atmosphere. However, at short time scales, precipitation events have two opposite impacts on the visibility [54]. During a heavy precipitation event, the visibility will be reduced, but after the end of precipitation event, the aerosols concentrations are likely to be lower, which will increase the visibility. In the first case, the visibility reduction is more likely induced by the hydrometeors that scatter the sun light while in the second case, the visibility increase is probably due to washout effect by precipitation [54].

\subsection{Interannual Coevolution of Visibility and Relative Humidity}

Visibility at a given location depends on the physical and chemical properties of the particulate matter and the ambient relative humidity. Specifically, aerosols grow in size when they interact with water vapour within high relative humidity conditions, inducing an increment in the aerosols sunlight scattering properties in the atmosphere [55]. One aspect in the debate on improving visibility which has not been sufficiently highlighted is the relative contribution of hydrophilic versus hydrophobic aerosols to visibility. Hydrophilic aerosols result in greater visibility impairment than hydrophobic aerosols since at high relative humidity (RH) hydrophilic aerosols attract more water than hydrophobic aerosols. Therefore, hydrophillic aerosols surface area is larger and their capability to scatter light out of the direct path between object and observer is enhanced [25]. The inter-annual evolution of visibility and relative humidity in Figure 6, clearly shows that there is a good one-to-one relationship between their variations and peaks. A decrease in relative humidity is associated with a decrease in visibility accordingly to their positive correlation coefficient of 0.87 and to an increase of dust surface mass concentration with a negative correlation coefficient of -0.81 in Table 1.

During the dry season, the average relative humidity varies from $40.31 \%$ (2007) to $52.90 \%$ (2000) (Figure 6(a)), while in the rainy season the relative humidity varies from $69.47 \%$ (2007) to $82.03 \%$ (2003) (Figure 6(b)). However, during the rainy season, the relative humidity was higher than 70\% (except 2007 with a value of 69.47\%) and the visibility varies from $8.62 \mathrm{~km}$ (2009) to 8.95 (2012). These observations confirms that low visibility in the Sahel were associated with low relative humidity. Worst visibility and high dust concentration occur under dry weather conditions with low relative humidity. Moreover, in the dry season when surface wind speed is higher, the dry weather conditions enhance dust emission and transport at the source and at regional scale. However, 


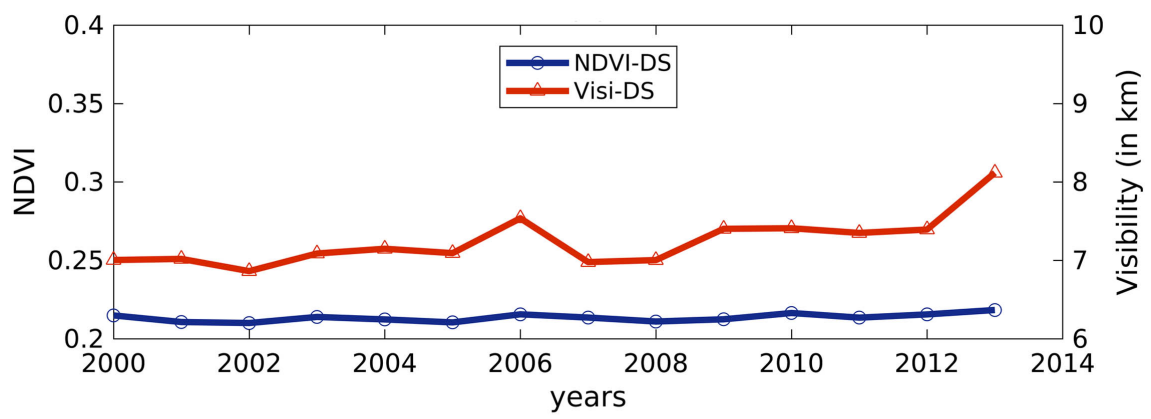

(a)

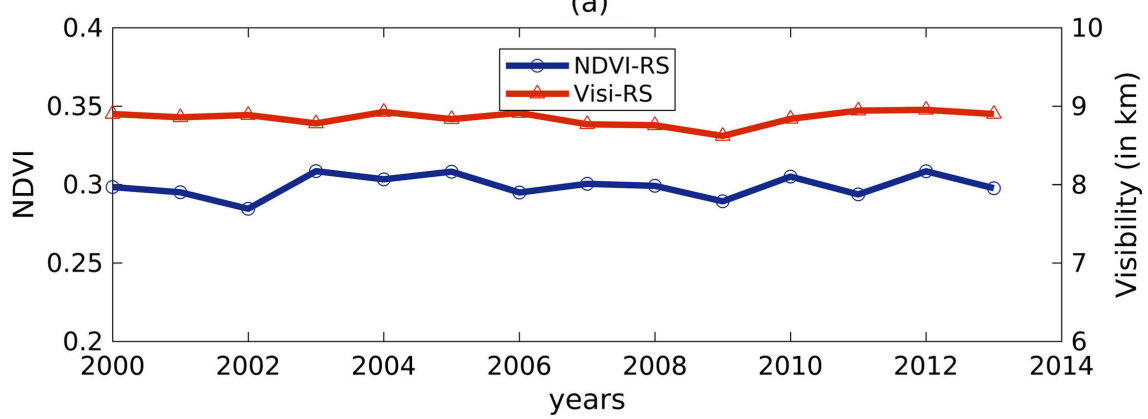

(b)

Figure 6. Evolution of visibility and relative humidity in the Sahel from 2000 to 2013 for (a) the dry season and (b) the rainy season.

during rainy season, the averaged visibility was less than $10 \mathrm{~km}$, underlining that high relative humidity in this period enhances water uptake by airborne particles, leading to higher light scattering and thus, visibility impairment.

In the dry season, low relative humidity in the Sahel is the consequence of a southward positions of the Inter-Tropical Convergence Zone (ITCZ) and the Harmattan winds which contribute to dust transportation increasing and therefore, to the visibility reduction at regional scale. Poor visibility was due to the influence of dust-laden (north-easterly) winds from the Sahara which transport a large quantity of dust as well as anthropogenic aerosols emitted at locally [41]. During the rainy season, the higher relative humidity is mainly due to the monsoon flow which is associated with rainfall in the Sahel that inhibits local dust aerosol emission into the atmosphere and contributes to the aerosols removal from the atmosphere through wet deposition or scavenging by atmospheric moisture [28]. Zhao et al. [12] showed that aerosol scattering efficiency in the atmosphere begins to increase when $\mathrm{RH}>50 \%$. Nwofor [56] showed that the atmospheric extinction values derived from the visibility data are analytically related to relative humidity in such a manner that at $\mathrm{RH}<60 \%$, the extinction tends to drop with $\mathrm{RH}$, while at $\mathrm{RH}>80 \%$ the extinction tends to rise moderately with RH. Nwofor [56] also suggested that $\mathrm{RH}<60 \%$ is encountered mainly in the dry season (Harmattan months) and associated with non-hygroscopic mineral dust aerosols advected from the Sahara, whereas $\mathrm{RH}>80 \%$ is encountered in the wet season and marginal growth in extinction with $\mathrm{RH}$ observed in some areas is associated with moderate hygroscopic particles possibly from sea salt and industrial emissions. 


\subsection{Interannual Coevolution of Visibility and Air Temperature}

Dust aerosol plays an important role in the radiation budget of the climate system. Dust aerosol can impact radiation balance via absorbing and scattering solar radiation [57]. Figure 7 represents the interannual coevolution of visibility and temperature in dry (a) and rainy (b) seasons from 2000 to 2013 . It shows an increase in the temperature and the visibility between 2000 and 2013. Temperature is positively correlated to visibility with a correlation coefficient of 0.58 and negatively correlated to dust surface mass concentration with a correlation coefficient of -0.48 (Table 1 ). At monthly time scale, we found that higher visibilities are noted in the warm and wet months of the year (June to September), while lower visibilities occur in the cold and dry months (October to May), but the weak correlations suggest that the links between temperature, dust concentration and visibility is complex and need further investigations. During the dry season, the yearly average temperature varies from $25.48^{\circ} \mathrm{C}$ (2000) to $27.79^{\circ} \mathrm{C}$ (2010) (Figure $7(\mathrm{a})$ ), while during the rainy season, temperature varies from $27.15^{\circ} \mathrm{C}(2000)$ to $28.22^{\circ} \mathrm{C}(2013)$ (Figure $7(\mathrm{~b})$ ).

Any previous studies have concluded that the correlations between visibility and temperature are weak and sometimes ambiguous [52] [58]. Xiao et al. [45] suggested that temperature is a factor indirectly influencing visibility variation. However, Vautard et al. [58] concluded that through radiation processes and by enabling less energy to be received at the surface during daytime, the low visibility phenomenon inhibits surface heating, and therefore induces a lower local temperature.

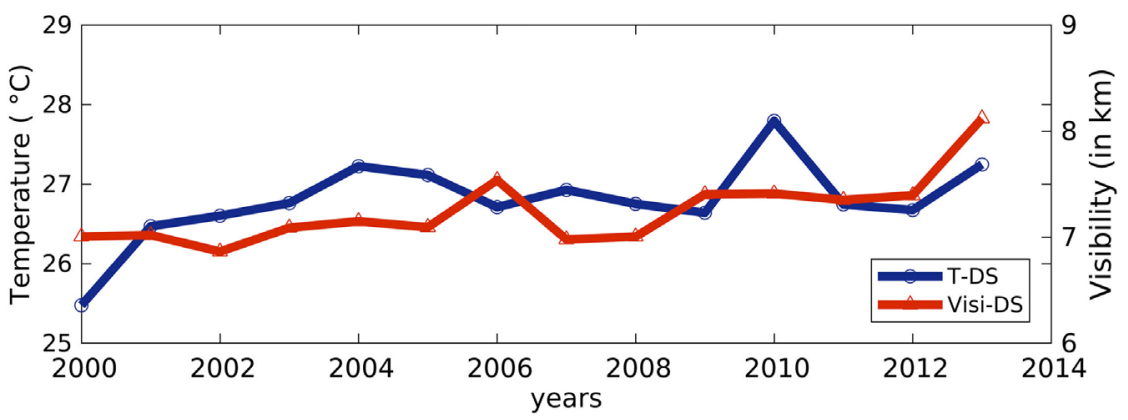

(a)

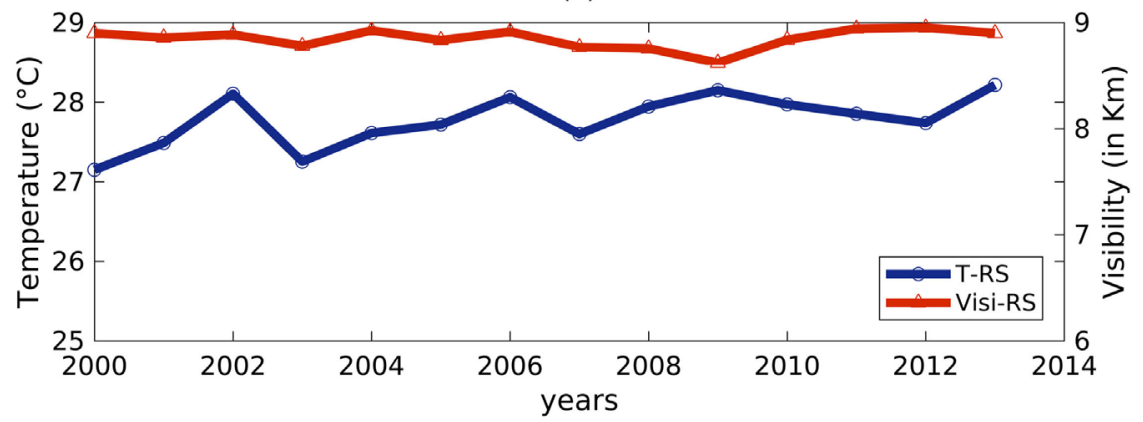

(b)

Figure 7. Evolution of visibility and temperature in the Sahel from 2000 to 2013 for (a) the dry season and (b) the rainy season. 


\subsection{Interannual Coevolution of Visibility and NDVI}

Solomos et al. [59] developed a time dependent dust source map for NMME-DREAM v1.0 model based on the satellite MODIS Normalized Digital Vegetation Index (NDVI). The results showed that areas with NDVI $<0.1$ were classified as active dust sources. Also, Kim et al. [60] developed a dynamical dust source map for the GOCART dust model by characterizing NDVI values $<0.15$ as active dust spots. Similarly, Vukovic et al. [61] combined MODIS land cover types with pixels having NDVI $<0.1$ to identify the seasonal dust sources that enforced the severe Phoenix haboob of July 2011 in the US. Figure 8 shows the interannual coevolution of visibility and NDVI in dry (a) and rainy (b) seasons from 2000 to 2013. The worst visibility and lowest NDVI are recorded in the dry season (Figure 8(a)), while the highest visibility and NDVI occurs in the rainy season (Figure 8(b)). The visibility during the rainy season varied between $8.62 \mathrm{~km}$ (2009) and $8.95 \mathrm{~km} \mathrm{(2012),} \mathrm{while} \mathrm{those} \mathrm{of} \mathrm{the} \mathrm{NDVI} \mathrm{were} \mathrm{in} \mathrm{the} \mathrm{range} \mathrm{of} 0.285$ (2002) to 0.309 (2003). However, visibility in the dry season were in the range of $6.86 \mathrm{~km}$ (2002) to $8.12 \mathrm{~km}$ (2013) with NDVI values, varying between 0.210 (2002 and 2005) and 0.218 (2013). Therefore, it can be concluded that during the dry seasons, low vegetation cover offers favourable conditions for dust mobilization, which resulted in an increase of dust content and low visibilities in the Sahel. In contrast, high vegetation cover during the rainy season may lead to low dust content and hence, improved visibilities. This is in agreement with Table 1 showing that NDVI was positively correlated to visibility and rainfall with correlation coefficients of 0.76 and 0.78 respectively and negatively correlated to

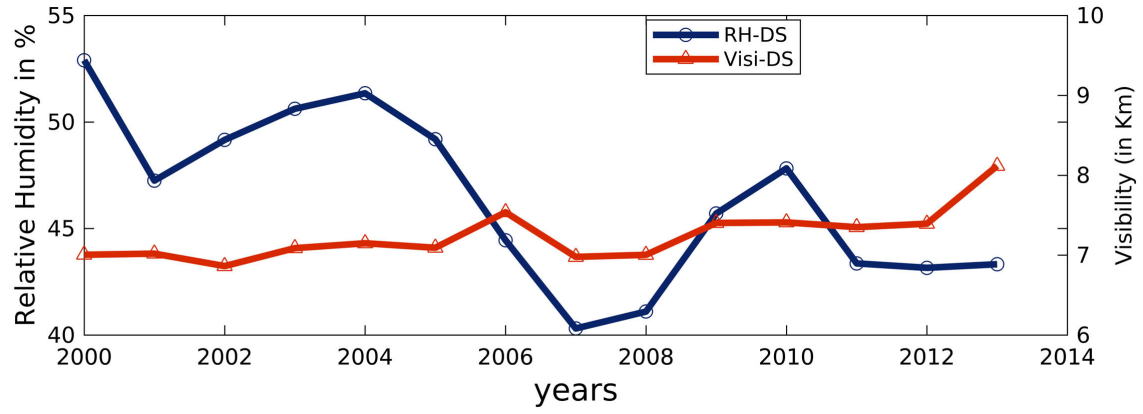

(a)

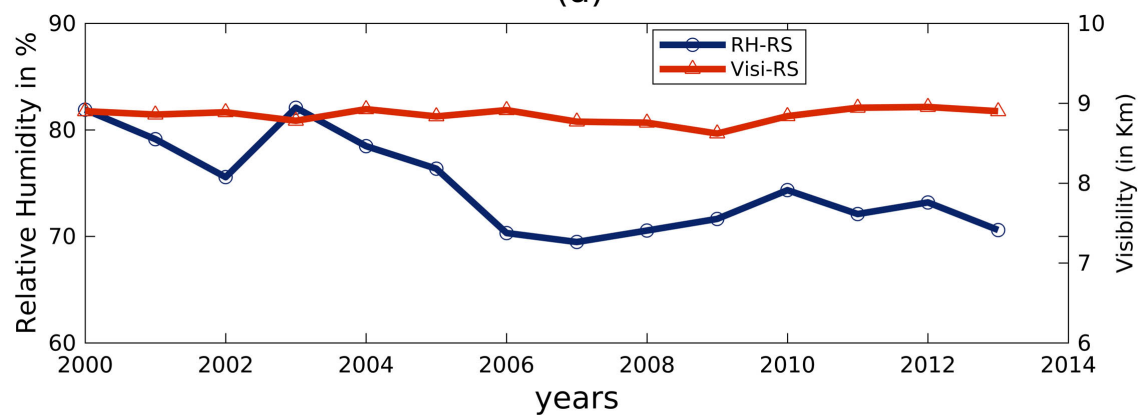

(b)

Figure 8. Evolution of visibility and NDVI in the Sahel from 2000 to 2013 for (a) the dry season and (b) the rainy season. 
dust surface mass concentration and wind speed with correlation coefficients of -0.77 and -0.79 respectively. This confirms that the increase of NDVI is associated with a high visibility and a low dust load, in conjunction with other meteorological conditions (e.g., rainfall and surface wind). Precipitation is needed for vegetation growth, and increasing vegetation coverage can reduce dust emissions. Therefore, as a direct reflection of the vegetation cover, NDVI value is positively correlated with precipitation and visibility, and negatively correlated with dust surface mass concentration with a low loading. Moreover, as a dynamic force of dust emissions, wind speed is negatively correlated with NDVI (Table 1).

In models, vegetation covers have been found to exert strong controls on dust emissions [59] [60] [61] [62]. Dust emissions are minor in densely vegetated surfaces and are subjected to high amounts in most semiarid and arid areas covered with little vegetation. Thus, vegetation is considered to be one of the main factors affecting dust emission and dust storm occurrence [62], since dust emission usually occurs on the bare surface, and indirectly affects dust emission via changing surface roughness. Higher vegetation cover results in higher surface roughness length and less dust emission, thereby reducing dust storm occurrence. Moreover, Zender and Kwon [29], comparing NDVI over the eastern Sahel to dustiness from the Total Ozone Mapping Spectrometer (TOMS) found that a lagged correlation of 9 - 10 months between NDVI and dustiness, after the initial greening of the Sahel due to the summertime precipitation. An increase in green vegetation is likely to affect roughness well beyond the main growing season.

Therefore, vegetation can contribute to the negative trends in winds through changes in the surface energy budget. Increased vegetation also reduces the area of bare soil available for dust emission [7]. In the Sahel, the positive trend in NDVI appears to be related mainly to an increase in the maximum NDVI in the growing season, while the length of the growing season remains unchanged [7] [63]. According to Evan et al. [30], correlations between Sahel NDVI and dust in the Tropical Atlantic region could be interpreted as signifying that vegetation in the Sahel exerts a certain control on the dust in the downwind areas, considering predominant trade flow. Cowie et al. [7] showed that a decrease in surface wind speeds associated with increased roughness due to more vegetation in the Sahel is the most likely cause of observed drop in dust emission. In contrast, Ridley et al. [2] suggested that the change in African dust emissions since the 1980s cannot be directly attributed to vegetation changes (including anthropogenic land use changes in the Sahel region). Therefore, a vegetation feedback on dust emission through surface roughness may be applicable on a local scale but appears less important for dust sources responsible for the trends in dustiness over the Atlantic. Also, human activities affect dynamics of dust storms indirectly via changing vegetation coverage and direct dust emissions [64]. All these findings corroborate our results, thereby suggesting that vegetation changes in the Sahel play an important role in variability of downwind dustiness. 


\section{Summary and Conclusions}

In this study, the long term trend of the observed visibility data used directly (without conversion into dust concentrations) over Sahel was investigated between 1957 and 2013. Then, to review factors of the atmosphere and of the land surface conditions that influence the visibility in the Sahel, the coevolution between the visibility and the dust surface mass concentration, the in-situ surface meteorological data (rainfall, relative humidity, wind speed, and air temperature), as well as the Normalized Difference Vegetation Index (NDVI) were analyzed from 2000 to 2013.

Visibility in the Sahel region was dramatically reduced in the 1970s and 1980s. The inter-annual variation of visibility in the Sahel was relatively weak during the period 1997-2013. Visibility in recent years (1997-2013) was lower than those in the 1970s and 1980s. Rainfall, relative humidity and vegetation are the main factors influencing dust mass concentration and consequently the horizontal visibility. The highest visibility, relative humidity, temperature and NDVI were recorded in the rainy season, while the highest dust surface mass concentration and wind speed were measured in the dry season. However, worst visibilities and lowest rainfall, $\mathrm{RH}$, air temperature and NDVI were recorded in the dry season, while lowest average dust surface mass concentration and wind speed were recorded in the rainy season. Better visibility in the rainy season suggests that dust is suppressed after a rainfall event, probably due to washout effect by precipitation and by the growth of vegetation following periods of rain. Increasing vegetation leads to bare soil reduction therefore to dust emission reduction. It is worth noting that the analysis of horizontal visibility in this study was based on the surface observation records, which lack sufficient data over the Sahel region. Also, Satellite observation and modeling studies with improved surface characterization will likely be important in clarifying the causes of the interannual variability of West African dust in future studies. In addition, the attribution of the trend did not give the contribution rate for each factor, which disenables this study to quantitatively identify the major causes of visibility impairment. Population growth can also have an impact on dust emission via changing the land surface features. For example, it is important to investigate to what extent agricultural activities in the Sahel could, or have, changed vegetation, wind, and thus, dust emission.

\section{Acknowledgements}

This paper is dedicated to the memory of the late Prof. Abdourahamane Konaré who contributed to this work. The visibility and meteorology data were provided by ASECNA (Agence pour la Securite de la Navigation Aerienne en Afrique et a Madagascar) and by Weather Underground (https://www.wunderground.com) which provides weather reports for most major cities across the world on its website. The authors would like to acknowledge the ASECNA and Weather Underground staffs for providing the data used in this study. MODIS NDVI data 
was retrieved from the online Data Pool, courtesy of the NASA EOSDIS Land Processes Distributed Active Archive Center (LP DAAC), USGS/Earth Resources Observation and Science (EROS) Center, Sioux Falls, South Dakota (https://lpdaac.usgs.gov/dataset_discovery/modis/modis_products_table/mod13 c2).

Dust Surface Mass Concentration used in this study was obtained from NASA/GIOVANNI processing team (https://giovanni.gsfc.nasa.gov/giovanni/).

\section{Funding}

This research was supported by the Education and Research Ministry of Côte d'Ivoire (MESRS), as part of the Debt Reduction-Development Contracts (C2Ds) managed by Institut de Recherche pour le Dévelppement, France (IRD).

\section{Conflicts of Interest}

The authors declare no conflict of interest regarding the publication of this paper.

\section{References}

[1] Rosenfeld, D., Rudich, Y. and Lahav, R. (2001) Desert Dust Suppressing Precipitation: A Possible Desertification Feedback Loop. Proceedings of the National Academy of Sciences of the United States of America, 98, 5975-5980. https://doi.org/10.1073/pnas.101122798

[2] Ridley, D., Heald, C. and Prospero, J. (2014) What Controls the Recent Changes in African Mineral Dust Aerosol across the Atlantic? Atmospheric Chemistry and Physics, 14, 5735-5747. https://doi.org/10.5194/acp-14-5735-2014

[3] Chen, S., Jiang, N., Huang, J., Xu, X., Zhang, H., Zang, Z., Huang, K., Xu, X., Wei, Y., Guan, X., et al. (2018) Quantifying Contributions of Natural and Anthropogenic Dust Emission from Different Climatic Regions. Atmospheric Environment, 191, 94-104. https://doi.org/10.1016/j.atmosenv.2018.07.043

[4] Stocker, T.F., Qin, D., Plattner, G.K., Alexander, L.V., Allen, S.K., Bindoff, N.L., Bréon, F.M., Church, J.A., Cubasch, U., Emori, S., et al. (2013) Technical Summary. In Climate Change 2013: The Physical Science Basis. Contribution of Working Group I to the Fifth Assessment Report of the Intergovernmental Panel on Climate Change. Cambridge University Press, Cambridge, 33-115.

[5] Choobari, O.A., Zawar-Reza, P. and Sturman, A. (2014) The Global Distribution of Mineral Dust and Its Impacts on the Climate System: A Review. Atmospheric Research, 138, 152-165. https://doi.org/10.1016/j.atmosres.2013.11.007

[6] Prospero, J.M. and Lamb, P.J. (2003) African Droughts and Dust Transport to the Caribbean: Climate Change Implications. Science, 302, 1024-1027.

[7] Cowie, S.M., Knippertz, P. and Marsham, J.H. (2013) Are Vegetation-Related Roughness Changes the Cause of the Recent Decrease in Dust Emission from the Sahel? Geophysical Research Letters, 40, 1868-1872. https://doi.org/10.1002/grl.50273

[8] Doherty, O.M., Riemer, N. and Hameed, S. (2014) Role of the Convergence Zone over West Africa in Controlling Saharan Mineral Dust Load and Transport in the Boreal Summer. Tellus B: Chemical and Physical Meteorology, 66, 23191.

[9] Evan, A.T., Fiedler, S., Zhao, C., Menut, L., Schepanski, K., Flamant, C. and Doher- 
ty, O. (2015) Derivation of an Observation-Based Map of North African Dust Emission. Aeolian Research, 16, 153-162. https://doi.org/10.1016/j.aeolia.2015.01.001

[10] Huneeus, N., Schulz, M., Balkanski, Y., Griesfeller, J., Prospero, M., Kinne, S., Bauer, S., Boucher, O., Chin, M., Dentener, F., et al. (2011) Global Dust Model Intercomparison in AeroCom Phase I. Atmospheric Chemistry and Physics, 11, 7781-7816. https://doi.org/10.5194/acp-11-7781-2011

[11] Davis, R.E. (1991) A Synoptic Climatological Analysis of Winter Visibility Trends in the Mideastern United States. Atmospheric Environment. Part B. Urban Atmosphere, 25, 165-175. https://doi.org/10.1016/0957-1272(91)90052-G

[12] Zhao, P., Zhang, X., Xu, X. and Zhao, X. (2011) Long-Term Visibility Trends and Characteristics in the Region of Beijing, Tianjin, and Hebei, China. Atmospheric Research, 101, 711-718. https://doi.org/10.1016/j.atmosres.2011.04.019

[13] Founda, D., Kazadzis, S., Mihalopoulos, N., Gerasopoulos, E., Lianou, M. and Raptis, P.I. (2016) Long-Term Visibility Variation in Athens (1931-2013): A Proxy for Local and Regional Atmospheric Aerosol Loads. Atmospheric Chemistry \& Physics, 16, 11219-11236. https://doi.org/10.5194/acp-16-11219-2016

[14] Mamouri, R.E., Ansmann, A., Nisantzi, A., Solomos, S., Kallos, G. and Hadjimitsis, D.G. (2016) Extreme Dust Storm over the Eastern Mediterranean in September 2015: Satellite, Lidar, and Surface Observations in the Cyprus Region. Atmospheric Chemistry and Physics, 16, 13711-13724. https://doi.org/10.5194/acp-16-13711-2016

[15] Ginoux, P., Prospero, J.M., Gill, T.E., Hsu, N.C. and Zhao, M. (2012) Global-Scale Attribution of Anthropogenic and Natural Dust Sources and Their Emission Rates Based on MODIS Deep Blue Aerosol Products. Reviews of Geophysics, 50, 3005. https://doi.org/10.1029/2012RG000388

[16] Hsu, N., Gautam, R., Sayer, A., Bettenhausen, C., Li, C., Jeong, M., Tsay, S.C. and Holben, B. (2012) Global and Regional Trends of Aerosol Optical Depth over Land and Ocean Using SeaWiFS Measurements from 1997 to 2010. Atmospheric Chemistry and Physics, 12, 8037-8053. https://doi.org/10.5194/acp-12-8037-2012

[17] Vandenbussche, S. and De Mazière, M. (2017) African Mineral Dust Sources: A Combined Analysis Based on 3D Dust Aerosols Distributions, Winds and Surface Parameters. Atmospheric Chemistry and Physics Discussions. https://doi.org/10.5194/acp-2017-809

[18] Ozer, P., Laghdaf, M.B.O.M., Lemine, S.O.M. and Gassani, J. (2007) Estimation of Air Quality Degradation Due to Saharan Dust at Nouakchott, Mauritania, from Horizontal Visibility Data. Water, Air, and Soil Pollution, 178, 79-87. https://doi.org/10.1007/s11270-006-9152-8

[19] Mahowald, N., Ballantine, J., Feddema, J. and Ramankutty, N. (2007) Global Trends in Visibility: Implications for Dust Sources. Atmospheric Chemistry and Physics, 7, 3309-3339. https://doi.org/10.5194/acp-7-3309-2007

[20] Mbourou, G.N., Bertrand, J. and Nicholson, S. (1997) The Diurnal and Seasonal Cycles of Wind-Borne Dust over Africa North of the Equator. Journal of Applied Meteorology, 36, 868-882. https://doi.org/10.1175/1520-0450(1997)036<0868:TDASCO>2.0.CO;2

[21] Cabello, M., Orza, J., Barrero, M., Gordo, E.,Berasaluce, A., Canton, L., Duenas, C., Fernandez, M. and Pérez, M. (2012) Spatial and Temporal Variation of the Impact of an Extreme Saharan Dust Event. Journal of Geophysical Research: Atmospheres, 117, 11204. https://doi.org/10.1029/2012JD017513

[22] Silue, S., Konare, A., Diedhiou, A., Yoboue, V., Toure, D.E., Assamoi, P., et al. (2013) 
Spatial and Temporal Variability of Windborne Dust in the Sahel-Sahara Zone in Relation with Synoptic Environment. Scientific Research and Essays, 8, 705-717.

[23] Baddock, M.C., Strong, C.L., Leys, J., Heidenreich, S., Tews, E. and McTainsh, G.H. (2014) A Visibility and Total Suspended Dust Relationship. Atmospheric Environment, 89, 329-336. https://doi.org/10.1016/j.atmosenv.2014.02.038

[24] Anjorin, F.O., Utah, E.U. and Buba, D. (2015) An Investigation on Effects of Harmattan Dust (aerosols) on Horizontal Visibility Deterioration over Bauchi, North-Eastern Nigeria. Iranica Journal of Energy and Environment, 6, 92-97.

[25] Boers, R., van Weele, M., van Meijgaard, E., Savenije, M., Siebesma, A., Bosveld, F. and Stammes, P. (2015) Observations and Projections of Visibility and Aerosol Optical Thickness (1956-2100) in the Netherlands: Impacts of Time-Varying Aerosol Composition and Hygroscopicity. Environmental Research Letters, 10, 015003.

[26] Madi, D., Kamal, O., Gholamali, M. and Ahmad, D. (2017) Estimation of Relationship Between Aerosol Optical Depth, PM10 and Visibility in Separation of Synoptic Codes, As Important Parameters in Researches Connected to Aerosols; Using Genetic Algorithm in Yazd. International Journal of Environmental Sciences Natural Resources, 7, . https://doi.org/10.19080/IJESNR.2017.07.555720

[27] Tsai, Y.I., Kuo, S.C., Lee, W.J., Chen, C.L. and Chen, P.T. (2007) Long-Term Visibility Trends in one Highly Urbanized, One Highly Industrialized, and Two Rural areas of Taiwan. Science of the Total Environment, 382, 324-341. https://doi.org/10.1016/j.scitotenv.2007.04.048

[28] Engelstaedter, S. and Washington, R. (2007) Atmospheric Controls on the Annual Cycle of North African Dust. Journal of Geophysical Research. Atmospheres, 112, D03103.

[29] Zender, C.S. and Kwon, E.Y. (2005) Regional Contrasts in Dust Emission Responses to Climate. Journal of Geophysical Research: Atmospheres, 110.

[30] Evan, A.T., Heidinger, A.K. and Knippertz, P. (2006) Analysis of Winter Dust Activity off the Coast of West Africa Using a New 24-Year over-Water Advanced Very High Resolution Radiometer Satellite Dust Climatology. Journal of Geophysical Research: Atmospheres, 111. https://doi.org/10.1029/2005JD006336

[31] Fensholt, R., Langanke, T., Rasmussen, K., Reenberg, A., Prince, S.D., Tucker, C., Scholes, R.J., Le, Q.B., Bondeau, A., Eastman, R., et al. (2012) Greenness in Semi-Arid Areas across the Globe 1981-2007-An Earth Observing Satellite Based Analysis of Trends and Drivers. Remote Sensing of Environment, 121, 144-158. https://doi.org/10.1016/j.rse.2012.01.017

[32] Evan, A.T. and Mukhopadhyay, S. (2010) African Dust over the Northern Tropical Atlantic: 1955-2008. Journal of Applied Meteorology and Climatology, 49, 2213-2229. https://doi.org/10.1175/2010JAMC2485.1

[33] Chiapello, I., Moulin, C. and Prospero, J.M. (2005) Understanding the Long-Term Variability of African Dust Transport across the Atlantic as Recorded in Both Barbados Surface Concentrations and Large-Scale Total Ozone Mapping Spectrometer (TOMS) Optical Thickness. Journal of Geophysical Research: Atmospheres, 110. https://doi.org/10.1029/2004JD005132

[34] Lin, M., Tao, J., Chan, C.Y., Cao, J.J., Zhang, Z.S., Zhu, L.H. and Zhang, R.J. (2012) Regression Analyses between Recent Air Quality and Visibility Changes in Megacities at Four Haze Regions in China. Aerosol and Air Quality Research, 12, 1049-1061. https://doi.org/10.4209/aaqr.2011.11.0220

[35] Gherboudj, I., Beegum, S.N. and Ghedira, H. (2017) Identifying Natural Dust Source regions over the Middle-East and North-Africa: Estimation of Dust Emission Poten- 
tial. Earth-Science Reviews, 165, 342-355.

https://doi.org/10.1016/j.earscirev.2016.12.010

[36] Ginoux, P., Prospero, J.M., Torres, O. and Chin, M. (2004) Long-Term Simulation of Global Dust Distribution with the GOCART Model: Correlation with North Atlantic Oscillation. Environmental Modelling \& Software, 19, 113-128. https://doi.org/10.1016/S1364-8152(03)00114-2

[37] Schepanski, K. (2018) Transport of Mineral Dust and Its Impact on Climate. Geosciences, 8, 151. https://doi.org/10.3390/geosciences8050151

[38] N'Datchoh, E., Diallo, I., Konare, A., Silue, S., Ogunjobi, K., Diedhiou, A. and Doumbia, M. (2018) Dust Induced Changes on the West African Summer Monsoon Features. International Journal of Climatology, 38, 452-466. https://doi.org/10.1002/joc.5187

[39] Mage, J.O. and Agber, J.N. (2017) Temperature Variability, Intensity of Wind Speed and Visibility during Harmattan in Makurdi Town, Nigeria. Journal of Research in National Development, 15, 198-206. https://www.ajol.info/journals/jorind

[40] N’Datchoh, E., Konaré, A., Diedhiou, A., Diawara, A., Quansah, E. and Assamoi, P. (2015) Effects of Climate Variability on Savannah Fire Regimes in West Africa. Earth System Dynamics, 6, 161-174. https://doi.org/10.5194/esd-6-161-2015

[41] Balarabe, M., Abdullah, K. and Nawawi, M. (2015) Long-Term Trend and Seasonal Variability of Horizontal Visibility in Nigerian Troposphere. Atmosphere, 6, 1462-1486. https://doi.org/10.3390/atmos6101462

[42] D’Almeida, G.A. (1986) A Model for Saharan Dust Transport. Journal of Climate and Applied Meteorology, 25, 903-916. https://doi.org/10.1175/1520-0450(1986)025<0903:AMFSDT>2.0.CO;2

[43] Mohamed, A.B., Frangi, J., Fontan, J. and Druilhet, A. (1992) Spatial and Temporal Variations of Atmospheric Turbidity and Related Parameters in Niger. Journal of Applied Meteorology, 31, 1286-1294. https://doi.org/10.1175/1520-0450(1992)031<1286:SATVOA >2.0.CO;2

[44] Camino, C., Cuevas, E., Basart, S., Alonso-Pérez, S., Baldasano, J., Terradellas, E., Marticorena, B., Rodriguez, S. and Berjon, A. (2015) An Empirical Equation to Estimate Mineral Dust Concentrations from Visibility Observations in Northern Africa. Aeolian Research, 16, 55-68. https://doi.org/10.1016/j.aeolia.2014.11.002

[45] Xiao, S., Wang, Q., Cao, J., Huang, R.J., Chen, W., Han, Y., Xu, H., Liu, S., Zhou, Y., Wang, P., et al. (2014) Long-Term Trends in Visibility and Impacts of Aerosol Composition on Visibility Impairment in Baoji, China. Atmospheric Research, 149, 88-95. https://doi.org/10.1016/j.atmosres.2014.06.006

[46] Li, Y., Zhao, H. and Wu, Y. (2015) Characteristics of Particulate Matter during Haze and Fog (Pollution) Episodes over Northeast China, Autumn 2013. Aerosol and Air Quality Research, 15, 853-864. https://doi.org/10.4209/aaqr.2014.08.0158

[47] Huang, L., Chen, M. and Hu, J. (2016) Twelve-Year Trends of PM10 and Visibility in the Hefei Metropolitan Area of China. Advances in Meteorology, 2016, Article ID: 4810796. https://doi.org/10.1155/2016/4810796

[48] Wu, J., Kurosaki, Y., Shinoda, M. and Kai, K. (2016) Regional Characteristics of Recent Dust Occurrence and Its Controlling Factors in East Asia. SOLA, 12, 187-191.

[49] Marticorena, B. (2014) Dust Production Mechanisms. In: Knippertz, P. and Stuut, J.B., Eds., Mineral Dust, Springer, Dordrecht, 93-120. https://doi.org/10.1007/978-94-017-8978-3_5

[50] Engelstaedter, S., Tegen, I. and Washington, R. (2006) North African Dust Emis- 
sions and Transport. Earth-Science Reviews, 79, 73-100.

https://doi.org/10.1016/j.earscirev.2006.06.004

[51] Zhao, H., Che, H., Ma, Y., Wang, Y., Yang, H., Liu, Y., Wang, Y., Wang, H. and Zhang, X. (2017) The Relationship of PM Variation with Visibility and Mixing-Layer Height under Hazy/Foggy Conditions in the Multi-Cities of Northeast China. International Journal of Environmental Research and Public Health, 14, 471. https://doi.org/10.3390/ijerph14050471

[52] Deng, J., Wang, T., Jiang, Z., Xie, M., Zhang, R., Huang, X. and Zhu, J. (2011) Characterization of Visibility and Its Affecting Factors over Nanjing, China. Atmospheric Research, 101, 681-691. https://doi.org/10.1016/j.atmosres.2011.04.016

[53] Goudie, A.S. and Middleton, N.J. (1992) The Changing Frequency of Dust Storms through Time. Climatic change, 20, 197-225.

https://doi.org/10.1007/BF00139839

[54] Majewski, G., Rogula-Kozlowska, W., Czechowski, P.O., Badyda, A. and Brandyk, A. (2015) The Impact of Selected Parameters on Visibility: First Results from a Long-Term Campaign in Warsaw, Poland. Atmosphere, 6, 1154-1174. https://doi.org/10.3390/atmos6081154

[55] Li, W., Shao, L. and Buseck, P. (2010) Haze Types in Beijing and the Influence of Agricultural Biomass Burning. Atmospheric Chemistry and Physics, 10, 8119-8130. https://doi.org/10.5194/acp-10-8119-2010

[56] Nwofor, O.K. (2010) Seasonal Levels of Meteorological Visibility at Port-Harcourt Nigeria and Possible Links to Aerosol Loading and Humidification. The Pacific Journal of Science and Technology, 11, 544.

[57] Chen, W.N., Chen, Y.C., Kuo, C.Y., Chou, C.H., Cheng, C.H., Huang, C.C., Chang, S.Y., Raman, M.R., Shang, W.L., Chuang, T.Y., et al. (2014) The Real-Time Method of Assessing the Contribution of Individual Sources on Visibility Degradation in Taichung. Science of the Total Environment, 497, 219-228. https://doi.org/10.1016/j.scitotenv.2014.07.120

[58] Vautard, R., Yiou, P. and Van Oldenborgh, G.J. (2009) Decline of Fog, Mist and Haze in Europe over the Past 30 Years. Nature Geoscience, 2, 115-119. https://doi.org/10.1038/ngeo414

[59] Solomos, S., Abuelgasim, A., Spyrou, C., Binietoglou, I. and Nickovic, S. (2018) Development of a Dynamic Dust-Source Map for NMME-DREAM v1.0 Model Based on MODIS NDVI over the Arabian Peninsula. Geoscientific Model Development Discussions, 12, 979-988. https://doi.org/10.5194/gmd-2018-251

[60] Kim, D., Chin, M., Bian, H., Tan, Q., Brown, M.E., Zheng, T., You, R., Diehl, T., Ginoux, P. and Kucsera, T. (2013) The Effect of the Dynamic Surface Bareness on Dust Source Function, Emission, and Distribution. Journal of Geophysical Research: Atmospheres, 118, 871-886. https://doi.org/10.1029/2012JD017907

[61] Vukovic, A., Vujadinovic, M., Pejanovic, G., Andric, J., Kumjian, M., Djurdjevic, V., Dacic, M., Prasad, A., El-Askary, H., Paris, B., et al. (2013) Numerical Simulation of "An American Haboob”. Atmospheric Chemistry \& Physics Discussions, 13, 3211-3230. https://doi.org/10.5194/acpd-13-26175-2013

[62] Engelstaedter, S., Kohfeld, K., Tegen, I. and Harrison, S. (2003) Controls of Dust Emissions by Vegetation and Topographic Depressions: An Evaluation Using Dust Storm Frequency Data. Geophysical Research Letters, 30. https://doi.org/10.1029/2002GL016471

[63] Heumann, B.W., Seaquist, J., Eklundh, L. and Jonsson, P. (2007) AVHRR Derived Phenological Change in the Sahel and Soudan, Africa, 1982-2005. Remote Sensing 
of Environment, 108, 385-392. https://doi.org/10.1016/j.rse.2006.11.025

[64] Aili, A., Oanh, N.T.K. and Abuduwaili, J. (2016) Variation Trends of Dust Storms in Relation to Meteorological Conditions and Anthropogenic Impacts in the Northeast Edge of the Taklimakan Desert, China. Open Journal of Air Pollution, 5, 127-143. https://doi.org/10.4236/ojap.2016.54010 